\title{
Hacia una gramática castellana para la escuela secundaria: opciones y desplazamientos a mediados del siglo XIX
}

\author{
Elvira Narvaja de Arnoux* \\ Universidad de Buenos Aires, Argentina
}

\begin{abstract}
Resumen
En la década del cincuenta del siglo XIX se publican en el ámbito hispánico gramáticas destinadas al nivel medio del sistema educativo, que deben definirse respecto de las que van a circular por la escuela primaria. Participan no solo en la consolidación de las subjetividades nacionales (gracias a la difusión de la lengua común) sino también en el disciplinamiento social (determinando la norma a la que deben ajustarse las prácticas) y en la reproducción de las estructuras sociales (formando a los miembros de la élite). El artículo se centra en el tramo referido a la sintaxis en cuatro textos aparecidos respectivamente en Buenos Aires, Santiago de Chile, Guanajuato y Madrid. Se consideran las unidades que establecen, el tratamiento de las figuras y el análisis que proponen en la ejercitación o en la ilustración recapituladora. El estudio permite apreciar las orientaciones que se van delineando pero también las diferentes perspectivas respecto del saber gramatical, de su función en la escuela secundaria y del sujeto que asiste a ella.
\end{abstract}

* Para correspondencia, dirigirse a: Elvira Narvaja de Arnoux (elviraarnoux@gmail. com), Instituto de Lingüística, Universidad de Buenos Aires, Capitán Ramón Freire 2323, $2^{\circ}$ 6, CP 1428, Ciudad Autónoma de Buenos Aires, Argentina. 
Palabras clave: gramáticas castellanas, escuela secundaria, enseñanza de la sintaxis, figuras, análisis gramatical.

TOWARDS A CASTILIAN GRAMMAR FOR SECONDARY SCHOOLS: CHOICES AND DISPLACEMENTS IN THE MID $19^{\text {TH }}$ CENTURY

\begin{abstract}
Some Castilian grammars intended for use in secondary school are published in the decade of 1850 . These grammars must be understood in relation with those used in primary school. They participate in the consolidation of national subjectivities (thanks to the spread of the common language), in social disciplining (determining the standard to be met by the practice) and in the reproduction of social structures (educating the members of the elite). The present paper refers to the subject of syntax in four texts published respectively in Buenos Aires, Santiago, Guanajuato and Madrid. We consider the units established in the grammars, the treatment of figures and the analysis they propose in exercises or in recapitulating illustrations. The study allows us to appreciate the guidance offered by grammars but also the different perspectives on grammatical knowledge, on its function in secondary school and on the subject who attends school.
\end{abstract}

Keywords: Castilian grammars, secondary school, teaching of syntax, figures, grammatical analysis.

Recibido: 27/10/14 Aceptado: 17/11/14

Las gramáticas en lenguas vernáculas europeas tuvieron un extenso desarrollo desde el Renacimiento. En muchos casos estaban ligadas a emprendimientos u objetivos pedagógicos, a los que los textos gramaticales se referían de una u otra manera. En una primera etapa se justificaban porque facilitaban el aprendizaje del latín y de las otras lenguas modernas o la enseñanza de la lengua propia como lengua extranjera. Pero con la progresiva afirmación de los Estados nacionales, la enseñanza del idioma patrio se consideró, con diferentes grados de explicitación, un instrumento de difusión y construcción del imaginario de lengua común homogénea, uno de los pilares que sostenían a aquellos. Incluso en el campo de las gramáticas generales este proceso se evidenció en el paso del estudio de los principios generales aplicables a las diversas lenguas a la enseñanza de la gramática de una lengua fundada en los principios de la gramática general (Arnoux 2012a). 
La enseñanza de la gramática de la lengua propia interviene, así, en la formación de las subjetividades nacionales que los Estados requerían, pero también en la normalización disciplinaria propia de las sociedades modernas. Si consideramos con Michel Foucault (2006) la importancia de los procesos de normalización en el desarrollo de aquellas, es evidente que las gramáticas constituyeron, a la vez que dispositivos generadores de subjetivación, instrumentos de disciplinamiento de las prácticas lingüísticas y de distinción de los grupos sociales. Al proponer una descripción de la lengua, prescribían los modos legítimos y permitían diferenciar a aquellos que los dominaban de los que tenían un manejo precario. Muchas gramáticas plantean la posibilidad de jerarquización de los sujetos a partir del dominio del uso correcto y la exclusión se justifica en el no sujetamiento a lo "normal", es decir, en la anormalidad de las prácticas censuradas. No es casual que fuera la gramática para la escuela secundaria, ámbito en el que se formarían los futuros ciudadanos (y particularmente en el siglo XIX las élites que se harían cargo del aparato estatal), un saber necesario dentro del dispositivo educativo de regulación, regularización y homogeneización de las conductas lingüísticas, iniciado en la escuela primaria. Adquiere en ese sentido un poder político en tanto destinado a sostener la gubernamentalidad de la sociedad a partir de la conducción de los comportamientos y de la formación de aquellos que deberían ejercerla. En relación con estos, la enseñanza de la gramática debería estimular, además, la capacidad de abstracción (asociada con la delimitación de clases lingüísticas más allá de la diversidad de realizaciones) y el reconocimiento de jerarquías sintácticas, entrenamientos que podrían proyectarse a otros ámbitos.

En la década del cincuenta del siglo XIX aparecen en diversos lugares del mundo hispánico manuales de gramática que se proponen para el tramo medio del sistema educativo antes de su expansión, consolidación y, en algunos casos, centralización estatal, que va a tener lugar en la segunda mitad del siglo. Si bien ya han aparecido otros textos de este tipo en los países considerados, particularmente en España, en esta década se definen con mayor claridad los destinatarios a los que se apunta, lo que va a dar lugar a dos clases de gramáticas (que se muestran, por ejemplo, en el Epítome y en el Compendio académicos que separan "oficialmente" los dos niveles): por un lado, las que atienden a los alumnos que cursan las "primeras letras" y, por el otro, las que contemplan a aquellos que asisten a los años superiores o a los cursos preparatorios para la universidad, a los que van a ser formados como maestros e, incluso, a aquellos que necesitan una orientación normativa en relación con la escritura. En relación con el segundo, grupo esto se evidencia en el cuerpo gramatical en la consideración de secuencias que exceden la oración simple (que es el marco al que va a restringirse la gramática de 
la escuela primaria) y en la necesidad de referirse a signos de puntuación variados, punto y coma, paréntesis y rayas, propios de los textos complejos, en los cuales habitualmente la pausa sintáctica fuerte marcada por el punto cierra una secuencia que puede integrar varias proposiciones.

La necesidad de atender a la diversidad de públicos se había expresado en las gramáticas mayores, como la de Bello y la de la Academia de 1854, en la implementación de recursos tipográficos para diferenciarlos pero esto mostró rápidamente su escasa eficacia, de allí la necesidad de operar editorialmente la separación y de definir desde el Estado su ámbito de difusión. En el Río de la Plata, por ejemplo, en relación con la escuela primaria, la gramática de Marcos Sastre de 1857 es uno de los primeros exponentes del tipo de gramática destinada a ese nivel y que cuenta con apoyo oficial, es decir, que está autorizada y recomendada para circular por el aparato educativo (Arnoux 2013).

Hemos elegido, en este trabajo, cuatro gramáticas destinadas a lo que globalmente podemos designar como los años superiores y hemos enfocado el tramo de la sintaxis para ver las opciones que se les presentaban a los autores de gramáticas en relación con las unidades que debían considerar, con las figuras (que resultaban de la tensión entre los esquemas gramaticales canónicos y las prácticas discursivas), y con los ejemplos y orientaciones pedagógicas tal como se planteaban en los tipos de análisis propuestos. Las vacilaciones y diferencias así como los aspectos comunes exponen las distintas temporalidades en las que se inscribían las diversas zonas del saber gramatical y las representaciones de género y de sujeto escolarizado que orientaban las decisiones que se tomaban. La búsqueda de una gramática adecuada a este nivel se evidencia en la afirmación progresiva de una perspectiva gramatical, diferente de la lógica y de la retórica (disciplinas con las que la gramática dialogaba, particularmente en el espacio escolar), que encuentra en la zona de la sintaxis la posibilidad de desplegarse. Los textos nos permiten entrever, entonces, un panorama de las diferentes perspectivas existentes en ese momento respecto de cómo debe encararse la enseñanza de la sintaxis en esa etapa del proceso educativo.

\section{LOS TEXTOS ABORDADOS Y ALGUNOS DATOS CONTEXTUALES}

Hemos seleccionado, así, cuatro manuales para la enseñanza media publicados en distintas ciudades del mundo hispánico en esa década: 
Principios elementales de gramática castellana recopilados de los mejores autores. Dispuestos para el uso de la juventud por D. V. (Buenos Aires, 1851), Compendio de gramática castellana, compuesto y arreglado a las doctrinas de la Gramática del Sr. D. Andrés Bello de José Olegario Reyes (Santiago de Chile, 1854), Compendio de la gramática castellana, con anotaciones para la ilustración de los profesores de primeras letras de Mathieu de Fossey (Guanajuato, 1855), y el Compendio de la gramática de la lengua castellana, dispuesto por la Real Academia Española, para la segunda enseñanza (Madrid, 1857). El término "compendio" en el título de los últimos tres parecen señalar cierta estabilización en relación con la enseñanza media, que consagra la RAE y que dominaron en las reformulaciones pedagógicas que se hicieron de la gramática de Salvá (Mourelle-Lema 1968) o en las de Gómez Hermosilla (Lépinette 2008) o Bello (Blanco 1997).

El caso emblemático es el Compendio de la RAE, derivado de la gramática académica de 1854, que tiene el estatuto de texto oficial, ya que la Ley Moyano, Ley de Instrucción Pública de 1857, establece en el artículo 88 que la Gramática de la Academia es texto obligatorio y único para la enseñanza pública, mostrando el profundo vínculo en ese momento de la RAE con el aparato estatal (Arnoux 2012b). Se afianza así el proceso de centralización del sistema educativo que había sufrido diversos avatares pero que implica en esa etapa la uniformización de los textos didácticos que van a circular por aquel. Si bien existen textos anteriores para la enseñanza de la lengua nacional en el nivel medio, con mayor o menor apoyo institucional, el gesto señalado muestra la importancia que ya tiene para las políticas estatales. En relación con la enseñanza del castellano en el sistema educativo un hito importante había sido en 1813 el Informe de la Junta creada por la Regencia para proponer los medios de proceder al arreglo de los diversos ramos de Instrucción Pública elaborado por Manuel José Quintana, “donde el castellano se impone como materia de estudio en los niveles primario y secundario y como lengua oficial en la Tercera enseñanza (la Universidad)" (Calero Vaquera 2008: 19-20). Se afirmaba así con un peso y un alcance mayores las decisiones anteriores, particularmente la de Carlos III en 1780, en la que establecía que no se admitiera a los alumnos a estudiar latinidad si no estaban bien instruidos en la gramática española. En la década del cuarenta del siglo XIX, por otra parte, ya se habían organizado los institutos de enseñanza media distribuidos en tres categorías: los superiores "en los que, además de los correspondientes a la enseñanza media, se cursaban estudios del nivel de la licenciatura y del doctorado en Filosofía"; los institutos de enseñanza media propiamente dichos; y los que impartían solo los primeros años de la enseñanza media (Lépinette 2008: 326). 
En los países hispanoamericanos ya existían escuelas que extendían la educación primaria o que preparaban para la universidad pero eran escasas y estaban claramente destinadas a la formación de la elite. Si bien esta orientación sociológica se mantuvo, a medida que avanzaba la segunda mitad del siglo se tendió a integrar progresivamente a otros sectores por requerimientos de las transformaciones sociales, entre otros, el avance de la sociedad industrial y la mayor ampliación del aparato estatal. En la década del cincuenta, en lo que va a ser el territorio de la República Argentina se reactiva, en el nivel secundario, el Colegio de Ciencias Morales en Buenos Aires, se crea el Colegio de Concepción del Uruguay en entre Ríos, se mantiene el Colegio Monserrat en Córdoba, se funda en Tucumán el Colegio de San Miguel, en Jujuy el de Dolores y en Corrientes el Colegio Argentino (Solari 2006). Pero el mayor impulso se da a partir de 1863 con la creación de Colegio Nacional de Buenos Aires a partir del de Ciencias Morales y la creación de los de Catamarca, Salta, San Juan, Tucumán y Mendoza hasta completar en 1898 la fundación de diecisiete colegios nacionales en el país (Puiggrós 2013).

En Chile, la Universidad, fundada en 1842, tenía responsabilidad sobre todo el sistema educativo en el marco de la importancia creciente asignada a los diferentes niveles de enseñanza, de lo cual eran prueba no solo la creación de escuelas primarias sino la puesta en marcha del sistema secundario a partir del Instituto Nacional, al que se agregan en 1849 ocho colegios más. El compendio de Reyes indica en la primera edición de 1854 la aprobación universitaria: "Conforme a lo acordado por el Consejo en sesión del 21 del que rije, a virtud del precedente informe, se aprueba para texto de enseñanza el "Compendio de Gramática Castellana" escrito por D. José Olegario Reyes". Cuenta con la firma del rector, Andrés Bello, a cuyas "doctrinas" se había atenido el texto. Cuando se lo publica en Buenos Aires en 1868, luego de trece ediciones en Chile, se señala la distancia que tiene con otros que no se asientan en criterios bien definidos: "defectuosos métodos que hoy se emplean para la enseñanza del idioma patrio, tales como Fernández, Alemani, Pujol y el más rutinario de todos de Herranz y Quirós, que jamás podrán suministrar a los estudiantes del ramo principios fijos sobre nuestra lengua" (IV). A esa distancia se había referido Juan D. Vico, con pareja evaluación, en su informe de inspección al Colegio del Uruguay (Entre Ríos) en $1863^{1}$. En él se señalan las diferencias entre los libros de texto disponibles

En Memoria presentada por el Ministro de Estado en el Departamento de Justicia, Culto e Instrucción pública al Congreso Legislativo de 1863, Buenos Aires: Bernheim y Boneo: 71-72 (la referencia está en Blanco 2005). 
destacando la existente entre los antiguos, sobre todo el manual de Herranz y Quirós (Madrid, $1834^{2}$ ) que tuvo numerosísimas reediciones y que circuló ampliamente, y el texto de Bello o sus reformulaciones, la primera de las cuales es la citada de Reyes.

Los otros dos textos que integran nuestro corpus, si bien no parten de un texto gramatical consagrado, también muestran el intento de atender a la conformación y futura ampliación del sistema medio de enseñanza. De uno de los autores, de Fossey, hemos podido encontrar datos biográficos que dan cuenta de sus vínculos con la puesta en marcha del sistema educativo en México ${ }^{3}$. Pero del otro, no hemos podido identificar el nombre del autor a partir de las iniciales D. V. (tanto Fermín Chávez 1973, como Juan María Gutiérrez 1915, lo citan de la misma manera sin aclaración alguna).

Mathieu de Fossey es un francés que muy joven se afincó en México ejerciendo como docente tanto en la capital como en Oaxaca, Guanajuato, Colima y Guadalajara, entre otras ciudades. En la portada del Compendio se presenta como "catedrático de gramática general e idioma castellano en el Colegio Nacional de Guanajuato, exdirector de las Escuelas normales de ambos sexos del mismo Estado y del territorio de Colima, miembro titular de la imperial Academia de Dijon y corresponsal de varias sociedades literarias". En el periódico El siglo XIX, el 12 de marzo de 1843 hay un aviso de la apertura del "Gimnasio Polígloto Científico", que se inicia diciendo "Don Mateo de Fossey, antiguo director del primer colegio francés establecido en México, después de varios años de ausencia, siempre consagrados a la enseñanza, ha vuelto a esta capital para fundar una nueva casa de educación". Su actuación como docente en el ámbito privado es conocida pero también sus vínculos con la educación pública, tal como lo señala al presentarse. Su preocupación por la formación de maestros lo llevó a intervenir en la fundación de la Escuela Normal de Guanajuato en la década del cuarenta por designación del gobernador Octaviano Muñoz Ledo (Munguía Escamilla 2010), a quien le dedica su gramática señalando "espero que la juventud mejicana y los que se quieran dedicar a la enseñanza de las primeras letras, sacarán igualmente de mi obra unos conocimientos que adquirirían muy difícilmente sin el socorro de ella". Moreno de Alba (2006) cita a de Fossey entre los gramáticos no mexicanos que alcanzaron prestigio durante la segunda mitad del siglo XIX, señalando las varias ediciones de su obra (por

\footnotetext{
2 Parece tener ya en 1837 una edición argentina (Juan María Gutiérrez, Origen y desarrollo de la Enseñanza Pública Superior en Buenos Aires ).

3 Agradezco el generoso aporte bibliográfico de Bárbara Cifuentes en relación con las actividades de De Fossey en México.
} 
ejemplo, la tercera, de 1874, posterior a su muerte acaecida en 1870). Nos da, además, datos ilustrativos de las publicaciones de gramáticas escolares en la época de De Fossey señalando que había adaptaciones de la GRAE y de Salvá pero no había ediciones mexicanas de Bello ni se habían preparado compendios de su gramática.

D. V., por su parte, no nos suministra datos personales e incluso firma su Introducción como "Compilador". Ya en el título había señalado que eran "principios elementales [...] recopilados" aunque no dé datos sobre las fuentes. Insiste en que sus destinatarios son los "jóvenes estudiantes", "la juventud estudiosa y ansiosa de saber". Inicia la introducción con una crítica global a las gramáticas existentes, que "precisan grandes reformas, ya porque tratan en sus pruebas de un modo tan superficial que no dejan la más remota idea, ya porque no están en nada conformes con las luces del día, y porque carecen de ciertos principios que son de absoluta necesidad". La perspectiva ilustrada adoptada ("las luces del día") se afirma también en el elogio del método: "el método de la construcción que es el más fácil, obvio y elegante hasta hoy conocido"4; "el método que seguimos aquí es el que está en práctica en los más célebres establecimientos de Europa y América".

El tratamiento de las fuentes a las que expresamente remiten las gramáticas estudiadas es distinto. Dos de los textos, el de Reyes y el Compendio de la Academia, parten, en cada caso, de un texto sobre el cual se operan reformulaciones de distinto tipo: el primero adapta la gramática de Bello y el otro reduce la de la RAE de 1854 suprimiendo determinados tramos (Arnoux 2012b). Las operaciones realizadas sobre las fuentes muestran dos concepciones del sujeto al que se dirigen, ya que el texto académico opera por supresión con lo cual dogmatiza el pensamiento gramatical expuesto en la fuente al excluir tramos que razonadamente dan cuenta de las opciones realizadas, mientras que el de Reyes hace una adaptación de la teoría de Bello construyendo un texto que atiende a la nueva situación, que es lo que finalmente va a dominar en las reformulaciones pedagógicas. Los otros dos corresponden, como señalamos, a autores individuales que se presentan integrando fuentes diversas (explicitadas o no) ya sea desde el mismo título o en los paratextos iniciales o en las notas a pie de página. Este último es el recurso que utiliza de Fossey para indicar sus fuentes: en la sección sintaxis, Mata y Araujo, Girault Duvivier, Noël y Chapsal, Clemencin, Martínez López y Salvá. D. V., en cambio, si bien se presenta como compilador no señala los autores en los que se basó.

4 En las citas de los textos gramaticales actualizo la ortografía. 
En todos los casos, los textos exponen, a su manera, la tensión entre el saber gramatical con sus diversas orientaciones, por un lado, y la representación del sujeto que va a ser escolarizado en este nivel y la función que se le asigna en él a la enseñanza gramatical, por el otro. Recordemos que el enseñar a pensar sostuvo insistentemente la presencia en esta área de los principios de la gramática general ${ }^{5}$, que a criterio de sus defensores simplificaba el aprendizaje gramatical y evitaba la memorización de reglas, pero esta opinión había sido ya discutida, sobre todo por Bello (Arnoux 2008). Para este gramático, el desarrollo de las actividades intelectuales no surgía de centrar el estudio en el vínculo entre lenguaje y pensamiento, que por otra parte no permitía estudiar lo específico de cada lengua, sino por el despliegue de un discurso razonado que diera razón de los hechos lingüísticos y aplicara criterios atentos a la racionalidad moderna, es decir, criterios uniformes y económicos. Así, una explicación gramatical "racional", y no los principios generales del lenguaje, iba a formar intelectualmente a los jóvenes y esa formación podría proyectarse a otras áreas. Asimismo, la gramática se fue perfilando como una herramienta para el aprendizaje de la escritura y la lectura de textos complejos, en lo cual los temas tradicionales de concordancia, particularmente, pero también de construcción y régimen colaboraban. A ello debía agregarse el estudio de las subordinadas en las oraciones complejas, ampliando la categoría de las incidentes al definir otros tipos y, más adelante, de la coordinación en las compuestas, aspectos propios de este nivel de enseñanza ya que la escuela primaria iba definiendo su límite, como dijimos, en la oración simple. Estos requerimientos llevaron a que ingresara el concepto retórico de período que permitía introducir el de oración (tal como se lo consideraría luego como segmento cuya autonomía sintáctica y sentido completo estaban marcados en la escritura por el punto), y a que se estabilizara el de complemento, dando lugar a diversas clasificaciones.

\footnotetext{
La presencia de la gramática general varió según los países, en lo que incidieron las decisiones que se tomaban en el campo educativo. García Folgado (2006: 657) recuerda para España el Reglamento General de Instrucción Pública de 1821, que regulaba por primera vez la segunda enseñanza, introduce la gramática general, además de la gramática castellana y la latina, en un plan oficial.
} 


\section{SOBRE LA SINTAXIS Y SUS UNIDADES}

En D. V., la caracterización de la sintaxis deriva de un razonamiento previo en el que la reunión de las palabras sirve para la expresión del pensamiento, apoyándose en las versiones difundidas de las gramáticas generales:

Si cada palabra de una lengua denota una idea de la cual es signo representativo, su reunión sirve para expresar un pensamiento completo. Mas la reunión de las palabras no es enteramente arbitraria: antes bien está sujeta a reglas determinadas. La Sintaxis, que prescribe estas reglas, trata por consiguiente del modo de unir las palabras para expresar bien los conceptos o para formar la proposición (99) .

El decurso que sigue es de lo más simple a lo más complejo: de las palabras a la proposición, del signo a cuya idea remite la palabra al pensamiento completo. Ambas series articulan la perspectiva lógica (centrada en el pensamiento) y la gramatical (que organiza las unidades lingüísticas). La sintaxis, que atiende a esto último, no es meramente descriptiva sino también prescriptiva ya que determina las reglas que unen las palabras "para expresar bien los conceptos o para formar la proposición". Esta última se presenta como la unidad que expresa un sentido completo (característica semántica de la oración tal como se va perfilando). La enunciación de un concepto requiere de reglas que la sintaxis determina. La insistencia en la relación lenguaje/pensamiento es propia de las gramáticas generales pero el criterio de la progresiva articulación de los términos (que puede inferirse de las reglas de "reunión de las palabras") expone algún desajuste derivado de fuentes anteriores y persistentes que parten de una concepción lineal y no jerárquica que describe la estructura del enunciado considerando un orden dado y en gran medida no permutable (Luis 1997), salvo cuando se hacen intervenir las "figuras". Pero también permite desplazar la proposición como esquema abstracto a la superficie discursiva, espacio de la enunciación gramatical del pensamiento. Los requerimientos pedagógicos, vinculados a la enseñanza del texto escrito, inciden posiblemente en esa orientación del razonamiento, lo que también se evidencia en lo que señala luego:

Mas como la proposición es susceptible de combinarse con otras, suspendiendo la conclusión del sentido hasta que se haya determinado

6 En la cita de las fuentes pongo entre paréntesis el número de la página correspondiente. 
el de estas partes intermedias, deben examinarse los diferentes casos en que se verifica esta combinación (100).

De allí que defina en esta presentación periodo, proposición principal, proposición incidente, proposición referencial y complemento, atendiendo, en primer lugar, a los espacios mayores del análisis:

Período es la reunión de dos o más proposiciones ligadas entre sí y dependientes de la proposición principal.

Proposición principal es aquella cuyo régimen o complemento pone término al período, y de la cual dependen las demás proposiciones.

Proposición incidente es la que está unida a algunos de los términos de la principal, por medio de un relativo.

Proposición referencial es la que se liga al sentido o concepto de la principal por medio de conjunciones o frases conjuntivas (100).

Luego, aborda el "complemento" entendido como aquello que "modifica el sentido de alguno de los términos de la proposición" (100) o el régimen directo o indirecto de cada una de las proposiciones (101), al que le agrega el "predicado" (que en gramáticas posteriores será el predicativo) cuando "es un adjetivo o un sustantivo adjetivado que se refiere al sujeto" (101). Para clasificar los complementos se apoya en la perspectiva latinizante de los casos por ser posiblemente la más difundida y lo que le permite diferenciar función de construcción: "el complemento es de tres modos y guía a cuatro casos, directo o acusativo, indirecto o dativo, de preposición u ordinario en los casos genitivo o ablativo" (103). El último engloba diversidad de posibilidades: "es el conjunto de dos o más palabras que modifican el sentido del signo o palabra a que se ligan" (104). Finalmente, atiende a la definición lógica de la proposición en sujeto y predicado considerando "las dos ideas de la que consta" (101) pero insiste en la perspectiva funcional al referirse al núcleo del sujeto ("sustantivo o palabra que haga su oficio"). Muestra de las vacilaciones en los criterios adoptados es la presencia de términos que remiten a clases de palabras y a tipos de modificadores; por ejemplo, al referirse a los modificadores del verbo habla de adjetivo, complemento o adverbio.

Reyes considera también la articulación de las palabras entre ellas ("enlace i conexión") en el marco de la frase entendida como oración, como proposición y como sintagma (en relación con este último, Bello habla de frase sustantiva, adjetiva y adverbial y frases complementarias). Conviven, así, representaciones asociadas con diferentes momentos: la proposición de las gramáticas generales, el período retórico que va a dar lugar a la oración tal como las gramáticas pedagógicas posteriores la han conocido ligada 
claramente a lo escrito y unidad jerárquicamente superior del análisis, y la frase como combinatoria primera que se integrará luego en el pensamiento gramatical estructuralista como constituyente inmediato. Pero en todos los casos se atiende a la manifestación discursiva:

Debiendo considerarse las palabras en la sintaxis según el enlace i conexión que tienen unas con otras, se han designado con los nombres de periodo, proposición, complemento, predicado, sujeto i atributo las diferentes frases que pueden formarse con aquellas (64).

Lo que le interesa marcar son los marcos y las unidades que debe tratar la sintaxis, diferentes de las clases de palabras ya que corresponden a las funciones (complemento, predicado, sujeto y atributo) que surgen de la descomposición de la oración, designación usada por Bello y que en Calleja, desde la perspectiva de los ideólogos, era el "pensamiento expresado" (Haßler 2012: 26). Calero Vaquera (2007) señala que el término de "complemento", que hace visibles las dependencias intraoracionales, no aparece en la gramática castellana hasta el siglo XIX y se vincula con el alejamiento de los conceptos de caso y régimen. Reyes reconoce en relación con el verbo: complemento directo o acusativo, indirecto o dativo y ordinario. Para el reconocimiento del directo, por ejemplo, recurre a la sustitución pronominal (lo, la) o a la transformación pasiva, es decir, a criterios netamente sintácticos. El período, por su parte, es necesario para considerar aquello que supera la enunciación de la proposición que se expondría en la oración simple. Bello, del cual parte, ya había hablado, como señalamos, en lugar de período, de oración (mostrando el paso de la retórica a la gramática) distinguiéndola de la proposición que puede no tener sentido completo (aunque articule sujeto y predicado o atributo) y que puede carecer de autonomía sintáctica; desplaza así la gramática de la proposición a la de la oración dándole a esta última el estatuto de marco del análisis sintáctico ya que la proposición puede conformar una oración o no. La proposición se desprende de su estatuto lógico, que Bello elude como una de las orientaciones de su obra, y pasa al gramatical:

Se llama oración toda proposición ó conjunto de proposiciones que forman sentido completo: de que está alfombrada la ribera es proposición perfecta pero no es oración (308: 84) 7 .

\footnotetext{
7 En las citas de Bello se indican entre paréntesis primero el número del apartado y luego el de la página.
} 
Reyes retoma la misma definición, sin el ejemplo, y se la asigna al período prefiriendo tal vez la forma léxica más difundida en el ámbito escolar y que permite articular arte de escribir y gramática. Asimismo reconoce los tipos de proposiciones desde el punto de vista sintáctico teniendo en cuenta la autonomía o la dependencia: absoluta o independiente, principal o subordinante, incidente o subordinada. Lo importante es que parte de una sintaxis enfocada en el marco de la oración y no de los temas tradicionales de concordancia y régimen que atendían a unidades menores y a sus vínculos - en un caso, correspondientes a los accidentes de ciertas partes variables de la oración; en el otro, a la dependencia de un segmento respecto de uno anterior-.

Las vacilaciones señaladas muestran una etapa de transición en la cual la concepción nueva de la sintaxis convive con cristalizaciones anteriores. El mismo Bello al comenzar su gramática dice que "la concordancia y el régimen forman la construcción o sintaxis", utilizando una equivalencia tradicional basada en la traducción al latín del griego (que ya había dejado de lado Du Marsais que diferenciaba las relaciones sintácticas que en el latín establecían los casos de la colocación de las palabras en la oración) pero que a Bello posiblemente le permita separar lo restrictivo que regula la gramática de los juegos que el hablante puede dar a su enunciado. Además redefine los términos indicando niveles en la restricción gramatical, más débil en un caso que en el otro -"la concordancia o armonía que entre varias clases de ellas (las palabras) ha establecido el uso, y su régimen o dependencia mutua" (6: 2) - a la vez que introduce la regulación del uso. Por otra parte, asociar el régimen a la dependencia mutua lo independiza del orden (las palabras que están antes rigen, las que están después son regidas).

De Fossey, al comienzo de su parte segunda, "De la sintaxis", señala el orden de exposición que va a seguir:

Ya dimos a conocer en la parte anterior ciertas propiedades de las voces: trataremos ahora de asignar a cada una de ellas el lugar que le corresponde respecto de su enlace con otras, dándole una denominación que indique su función en la proposición. Pero antes diremos algo de lo que se entiende por concordancia, régimen, construcción de las partes de la oración, y sintaxis natural y figurada (64).

La sintaxis se presenta como una prolongación de la analogía (incluso va a cerrar el tramo con "sintaxis de las partes de la oración") y no deja de lado los aspectos tradicionales (concordancia, régimen, construcción) pero introduce el tema de la función y plantea como marco la proposición, siguiendo en esto la tradición de las gramáticas generales para las que constituye el modelo según el cual se establece toda enunciación, el resto se desprende de esto 
por reducción o explicitación (Chevalier 1968). Al referirse a la proposición indica que es el nombre que se le da a la oración si es simple, ya que si es compleja se la llama periodo, en la que los miembros "se pueden convertir en otras tantas proposiciones" (68), lo que se determina a partir de la presencia de un verbo conjugado, y estas proposiciones son principales (absolutas o relativas) o incidentes (en lo que engloba todo tipo de proposición subordinada). Oración y función son marcas de lo que se va a imponer en la enseñanza escolar de la gramática. Como señalamos, la designación período, vinculada con la tradición retórica, va a tender a desaparecer del espacio gramatical (aunque nuestros autores, en general, no puedan eludirla) y la de proposición a concentrarse en las subordinadas. La inserción de la construcción como parte de la sintaxis expone el desplazamiento que se ha ido dando de la identificación a la consideración de aquella como una temática peculiar interna a la sintaxis (Calero Vaquera 1986).

El Compendio usa oración como enunciación o proposición, aunque cuando indica los tipos sigue a la gramática académica de 1854 (que, a su vez, retoma en esto la de 1796, Gómez Asencio 2014) que señala al clasificarlas en primeras y segundas:

[...] veamos cuántas y cuáles son las oraciones que resultan de los preceptos anteriores, que es lo mismo que reducir a ciertas fórmulas las varias proposiciones o enunciaciones que sirven para declarar nuestros pensamientos (165).

Oración, en este caso, es el enunciado de un esquema gramatical que resulta del tipo de verbo que la gobierna (transitivo, intransitivo, activo, reflexivo, impersonal...) y del orden lineal de los constituyentes y de la aparición (primeras) o no (segundas) de los segmentos esenciales, en lo que incide posiblemente la vieja noción de la oratio perfecta (Stefanini 1994). En ese desarrollo se introducen las oraciones de relativo:

Cuando el pensamiento que se quiere declarar no se puede comprender en una oración, sino que ha de ir pendiente de una a otra, se introduce un pronombre relativo, y de él toma este nombre la oración, v.gr.: Pedro, QUE ESTÁ VIAJANDO, desea aprender (112).

Cuando ambos textos, la fuente y el que la reformula, suministran los ejemplos de sintaxis regular y figurada nos encontramos con "períodos" no designados como tales. La enseñanza gramatical, profundamente ligada a la enseñanza de la escritura, no puede dejar de lado los segmentos que marcan la unidad semántica y la autonomía gracias al punto y que llevan a "la formulación moderna de la oración [phrase en el original] como conjunto 
jerarquizado de proposiciones que forman un sentido completo" (Seguin 1993: 459).

A la sintaxis se refieren en estos términos:

Sintaxis es el órden y la dependencia que las palabras deben tener entre sí para formar la oración. Este órden es de dos modos, regular y figurado. Regular se llama aquel en que se siguen estrictamente las reglas gramaticales; figurado es el que se observa para dar más vigor y elegancia á las oraciones, usando algunas licencias que se llaman figuras ó adornos de la oración.

[...] Los principios generales de la Sintáxis no figurada, se reducen á tres, concordancia, régimen y construcción.

Se anuncian al hablar de "orden y dependencia" las partes tradicionales: construcción para lo primero, concordancia y régimen para la segunda. La distinción entre regular y figurado le permite diferenciar el espacio de las reglas (obligatorias sobre todo en la concordancia y el régimen) y el de la posible libertad del hablante asociada a la construcción.

Si bien todos los textos atienden a la subordinación y a lo que se va a designar como oración compleja, aunque los tipos que contemplan varíen, no se considera la compuesta, generada por la coordinación o yuxtaposición de proposiciones del más alto nivel sintáctico. En ese sentido, Gómez Asencio (1987) ya había señalado su introducción tardía en la reflexión gramatical hispánica.

\section{EN TORNO A LAS FIGURAS}

El tema de las figuras constituye un resto persistente de la reflexión sobre el orden en las gramáticas de las lenguas vernáculas europeas. La necesidad de establecer un orden "natural" o directo impone, a la vez, frente a la construcción diversa de las producciones verbales, considerar lo que lo transgrede pero que no puede dejar de ser admitido, de allí que se lo asocie con valoraciones extragramaticales: las figuras dan mayor elegancia o vigor a las frases. La reflexión sobre las figuras y, sobre todo, el hipérbaton va a permitir atender, además, con mayor precisión las colocaciones de los modificadores en relación con un núcleo y considerar las diferencias de sentido que en algunos casos, como los de colocación del adjetivo, implican. En las otras figuras que se relevan, las transgresiones muestran también 
requerimientos pragmáticos o de perfilamiento del referente o de cambios en la función "natural" de una palabra o en el valor temporal del verbo.

D. V. reconoce cuatro figuras:

$1^{\mathrm{a}}$ hipérbaton o inversión del orden natural; $2^{\mathrm{a}}$ pleonasmo o aumento de palabras; $3^{\mathrm{a}}$ elipsis o supresión de palabras; y $4^{\mathrm{a}}$ silepsis o falta de concordancia (111).

El marco en el que las aborda es la construcción, entendida como el orden en el que se colocan las palabras, aunque la inversión sería la única que estrictamente correspondería a ello: aquella en la que "por dar a las palabras elegancia o energía las trasladamos o invertimos en orden contrario al que sigue la operación mental". Se sigue en este caso, según el autor, que se inscribe en una larga tradición, un orden arbitrario o artificial, opuesto al natural en el que el orden canónico sería sujeto, verbo activo, complemento acusativo, dativo y ordinario; si el verbo es de otro tipo, se prescribe el siguiente orden "los complementos ordinarios que lo modifiquen deberán colocarse después del adjetivo que se refiere al sujeto y antes del adverbio si concurren este y aquel en la proposición" (111).

Reyes se refiere también a las figuras en el apartado sobre la construcción, pero es el cierre de una larga exposición sobre la colocación del adjetivo respecto del sustantivo, tanto las facultativas como las obligatorias, y de los modificadores del verbo:

En la construcción del verbo notaremos que, si es activo, se coloca inmediatamente después de él el complemento indirecto, después el ordinario i últimamente el adverbio, siempre que no sea el negativo no, pues en caso de serlo deberá colocarse antes del verbo (79).

Destina un fragmento importante a la ubicación de los pronombres clíticos (designados según su posición como afijos o enclíticos). El desarrollo se acompaña de una dimensión normativa marcada, en la que sigue a Bello (932: 245):

[nota] Cuide el institutor de hacer notar a sus alumnos las construcciones viciosas me se, te se, que hemos oído hasta en personas educadas, diciendo vg: me se fue, te se- olvidó.

Condena también un uso ligado a género o registro:

Cuando el sujeto precede al verbo se emplearán precisamente afijos y no enclíticos. Es un vicio decir el libro cayósele de las manos, en vez de se le cayó, como dicen los escritores correctos (79). 
El tema de las figuras le permite, entonces, atender a fenómenos gramaticales importantes como la colocación del adjetivo o de los clíticos. La perspectiva que adopta en el tratamiento de la construcción es amplia, ya que reconoce fenómenos más restrictivos debido al cambio de significado que la posición del término implica, al uso habitual o a criterios normativos pero admite el juego del hablante:

El orden que deben guardar los afijos y enclíticos o el negativo no con respecto al verbo, y ciertos adjetivos con relación al sustantivo es necesario para la corrección del lenguaje; pero no sucede lo mismo con las demás palabras que modifican al verbo o al sustantivo, dependiendo esto del giro que cada cual quiera darle para su mayor fuerza y elegancia (79).

La introducción de las figuras, insoslayable en la medida en que todavía persiste en el espacio gramatical el tema de la construcción natural o artificial, se hace así también a partir del hipérbaton pero articulado claramente con los vínculos sintácticos que ha señalado antes:

Colocando las palabras según las reglas establecidas obtendremos la construcción natural; e invirtiendo su orden, en los casos en los que no se opongan dichas reglas, resultará la construcción artificial, es decir, la figura llamada hipérbaton (80).

A ella siguen las que había enunciado también D. V., "que se hallan autorizadas por el uso, y ocurren con más o menos frecuencia en castellano":

Si suprimimos una o varias palabras que pueden sobreentenderse, tendrá lugar la figura llamada elipsis.

Si aumentamos una o varias palabras para dar más fuerza o energía a la expresión, tendremos la figura llamada pleonasmo.

Finalmente, si faltamos a las reglas de concordancia, para el mejor sonido de las palabras o para darles su verdadero sentido, se cometerá la figura llamada silepsis (80).

En el cierre del apartado, la dimensión normativa vuelve a aparecer, sensible a los requerimientos de las prácticas escolares, ya que señala que "hay dos vicios que vemos cometerse a cada paso, particularmente por la gente vulgar, y con los cuales no transigirá jamás la buena locución: el barbarismo y el solecismo" (80).

De Fossey integra también el tema de las figuras en el tramo destinado a la construcción, que le va a permitir hablar de sintaxis natural y sintaxis figurada, pero no restringiéndose a la problemática del orden: 
La sintaxis natural es la colocación de las palabras y oraciones según el orden natural de las ideas; y sintaxis figurada es aquella que para mayor elegancia de las oraciones permite algunas licencias, ya alterando el orden de las palabras, ya omitiendo unas o añadiendo otras, ya quebrantando las reglas de concordancia (66).

A las figuras indicadas por los otros autores agrega la enálage, figura que parte de la idea de que las palabras pertenecen naturalmente a una clase (no que pueden cumplir funciones distintas):

Enálage es la figura por la cual se pone una parte de la oración por otra, como: el saber aprovecha en todas ocasiones -es preciso conocer el porqué de las cosas-el sí de las niñas; en cuyos ejemplos saber, porqué y si hacen veces de nombres (67).

El Compendio abre la parte de la sintaxis refiriéndose al orden regular, retomando la tradicional concepción de que va adelante lo que tiene "antelación por naturaleza, dignidad o importancia" (93). Encara la sintaxis figurada luego de un extenso desarrollo del tema de la construcción y de los tipos de oraciones. En esas partes anteriores opone la construcción al régimen por la mayor libertad que en aquella puede tener la colocación de las palabras. Señala las posibilidades de acompañamiento del sustantivo y del verbo y se detiene en la "construcción del verbo con el pronombre", que es como en el caso de Reyes la zona donde se despliega la dimensión normativa. Por un lado, en relación con los pronombres de tercera persona en dativo y acusativo:

El modo de usar el pronombre de tercera persona en dativo y acusativo de singular y plural, es lo que ofrece mayor dificultad, por las diversas opiniones que sobre el particular han seguido y siguen todavía escritores de nota. La Academia, habiendo de optar entre ellas, se ha atenido a la más autorizada señalando la variante le para dativo singular de masculino y femenino $[\ldots]$

Para el acusativo en género masculino se admiten indistintamente el le y el lo. Podrá pues decirse: Antonio compuso un libro y lo imprimió, o le imprimió, mientras con el transcurso del tiempo no dé la costumbre marcada preferencia al lo sobre el le, o viceversa (108).

Se refiere también, entre otros, a la colocación de los clíticos:

Cuando los pronombres personales son términos de los verbos, se usan en su construcción antepuestos o pospuestos, y así se dice: ME amas; -TE aborrecen; -SE estiman; -ME duermo; y también: ámas ME; aborrécenTE; estímanSE; duérmoME. 
Recomendamos, no obstante, una prudente sobriedad en la práctica de posponer el pronombre al verbo, porque de ella suelen resultar vocablos de ingrato sonido (109).

Ese desarrollo previo lleva a la siguiente caracterización de la sintaxis figurada, en la que aparecen otros casos además del que altera el orden:

Sintaxis figurada o adornada es aquella que, para mayor energía y elegancia de las expresiones, permite algunas licencias en la regular, ya alterando el orden y colocación de las palabras, ya omitiendo unas, ya añadiendo otras, ya quebrantando las reglas de la concordancia. Estas licencias, autorizadas por el uso, se llaman figuras o adornos de la oración (113).

Analiza luego las cuatro tradicionales (hipérbaton, elipsis, pleonasmo y silepsis) a las que agrega la traslación, ejemplificada a partir de datos de la situación:

Se hace uso de esta figura cuando a ciertos tiempos de los verbos se da una significación que ordinariamente no tienen; por ejemplo, cuando a un deudor se le dice: ME HAS DE PAGAR, en vez de págame; a un criado: ME TRAERÁS, en lugar de tráeme un vaso de agua; a un amigo: mañana SALGO, esto es, saldré para Segovia (122).

En relación con el hipérbaton trata sobre todo la colocación de los adjetivos, las formas de tratamiento, los relativos. El uso general, la práctica o los buenos escritores aparecen como los orientadores para las dobles posibilidades:

Los vocablos cierto, pobre, mero, simple, y algunos más, deben preceder o seguir a los sustantivos o adjetivos con que conciertan, según el concepto en que se emplean, pues tienen más de uno: la práctica es para esto guía suficiente.

El comentario final sobre esta figura deja de lado el esquematismo de las gramáticas y muestra el interés que para el aprendizaje de la escritura tiene la reflexión sobre el discurso:

Otras muestras de inversión gramatical pudiéramos añadir, sin que ellas solas sirviesen de seguro norte a la juventud estudiosa para no extraviarse en el empleo del hipérbaton, figura a que tanto se presta la lengua castellana, y en la cual es por lo mismo muy ocasionado el abuso. A falta pues de reglas más precisas, recomendamos el estudio de los buenos escritores y el trato con personas doctas; pero advirtiendo de paso que no suele consentir la prosa muchos de los giros que dan gala y brío 
a los versos, o que excusa lo artificioso de su construcción. Por último, conviene tener muy presente que a las dotes de elegancia, vehemencia y eufonía, debe en todo caso preferirse la de la claridad, sin la cual son superfluos todos los demás adornos del lenguaje (118).

En relación con la elipsis, los criterios para su uso son, en gran medida, pragmáticos: "esta figura requiere que las palabras omitidas sean de aquellas que suple sin trabajo la persona con quien se habla, y que con la brevedad de la cláusula se evite la redundancia y pesadez que en otro caso tendría" (119). Los ejemplos, en este caso, provienen de la vida cotidiana y de las relaciones cara a cara: "A veces los vocablos omitidos por la figura elipsis se suplen con el gesto o con la acción, lo cual es más fácil de comprender que de explicar" (120).

Del pleonasmo se resalta su función intensificadora: "se emplea para dar más fuerza a la expresión, y para que a las personas que nos oyen no quede duda alguna de lo que les queremos referir o asegurar" (120). Y en cuanto a la silepsis se insiste en el centramiento en la referencia: "es porque atendemos a lo que representan, y no a lo que dicen". Así, por ejemplo "se usa cuando no concertamos los verbos en el número singular con nombres colectivos del mismo número, sino en plural con la multitud que representan" (121).

\section{EJEMPLOS Y ORIENTACIONES PEDAGÓGICAS PARA EL ANÁLISIS}

Los textos proponen modelos de análisis que ilustran y tienden a fijar los conceptos desarrollados. Entre el análisis gramatical, que define la naturaleza y función de las palabras aisladas y el análisis lógico, que define la naturaleza y función de las proposiciones (Chevalier 1979), se dan opciones y combinaciones diversas. El segundo se va orientando a lo que en la escuela secundaria se afirmará como análisis sintáctico, que privilegia jerárquicamente los miembros de la oración. Los ejemplos, sean o no de autor, provienen de la tradición escrita. Los enunciados elegidos exponen modelos de comportamiento individual o político, remiten a un universo discursivo prestigioso o ponen en contacto al estudiante con personajes o escenas de un espacio histórico que debe conocer. Su función formativa acompaña estas muestras de lengua destinadas al análisis. 
D. V., bajo el título "Ejemplo de un periodo", delimita, primero, las proposiciones. El segmento destinado al análisis tiene como es habitual un fin formador o moralizante que refuerza la enseñanza escolar de la gramática:

El joven, que tiene aplicación al estudio, consigue ilustrar su entendimiento, cuando no da entrada a los vicios, que le perturban y desmoralizan.

Se desplaza entre lo gramatical y la perspectiva lógica, ya que si bien delimita las proposiciones y se refiere al complemento no reconoce como cierre de la oración / período la marca de puntuación sino lo que considera nuclear del sentido (privilegiando una jerarquía entre las proposiciones que no atiende a la primera separación entre sujeto y atributo/predicado) y no contempla en esta etapa a la incidente inserta en la referencial:

En este ejemplo la palabra que pone término al periodo es entendimiento, las demás solo sirven para ilustrar dicho régimen. La proposición principal es el joven consigue ilustrar su entendimiento: la incidente, que tiene aplicación al estudio: la referencial, cuando no da entrada a los vicios, que le perturban y desmoralizan: y el complemento es el régimen directo e indirecto de cada una de las proposiciones citadas (101).

Reducido el período a las proposiciones que lo integran, enuncia, luego, lo que es descomponer una proposición, es decir, en la tradición de las gramáticas logicistas "determinar primeramente las dos ideas de que consta: esto es la del sujeto y la del atributo". Señala las clases de palabras que corresponden a cada una, sustantivo o "palabra que haga su oficio" y verbo, e indica los posibles modificadores: en un caso, adjetivo, complemento y proposición incidente; en el otro, adjetivo, complemento o adverbio.

En la parte final del tramo destinado a la sintaxis expone el análisis analógico y sintáctico, al que llama análisis gramatical (en el que domina la caracterización palabra a palabra) y, luego, el análisis de las proposiciones. En el primero usa el sistema de cuadros a cuatro columnas; en el analógico cada columna se ubica luego de poner la palabra (por ej., "placeres"), su naturaleza (sustantivo), su especie (abstracto), su modificación (masculino plural), es decir, que se caracteriza cada palabra en sí. En el sintáctico introduce en la primera columna no palabras sueltas como en el anterior sino articuladas en una frase, lo que permite en la columna "su especie" agregar a concreto, determinativo, calificativo, otras posibilidades: transitivo (para el verbo) o invariable (para la preposición). Reemplaza "su modificación" por "sus funciones" atendiendo a los vínculos sintácticos de una palabra con otra: Tú (sujeto de leerás), leerás (designa la acción de tú), la (determina lección), 
lección (complemento directo de leerás). El análisis de las proposiciones lo encara a través de preguntas y respuestas posibles en el ámbito de la clase, privilegiando el significado (este criterio cuya larga tradición escolar conocemos se distancia del criterio sintáctico tal como Bello lo plantea). Abundan las indicaciones para el que enseña. Al que se le proponen las preguntas que le permitirán al estudiante determinar en un primer momento las funciones:

Dícesele al discípulo que explique analíticamente todas las palabras de esa proposición. Comience así: $1^{\circ}$ iquién es un sabio? [en ese hombre es un sabio] -Ese hombre (sujeto determinado por medio del adjetivo determinativo ese), $2^{\circ}$ ¿Qué es ese hombre? -Un sabio (atributo del sujeto hombre, adjetivo calificativo y complemento directo del verbo es).

El plan no puede ser más simple ni parecer con más claridad. -Debe ponerse gran cuidado para conocer y distinguir el verbo transitivo del intransitivo, esto se conseguirá con preguntarse: $-1^{\circ}$ ¿Quién hace, hizo o hará? ¿Quién o qué es, fue o será hecho?

Bajo el título de "práctica" a partir de un enunciado se despliegan las preguntas y respuestas. Se estimula; además, la manipulación de los segmentos para efectuar comprobaciones gramaticales, cuya operación fundamental es la reducción / transformación a la estructura básica de la proposición:

\section{El honor y el dinero son apetecibles}

P. Nombrad las partes de esa frase.

R. El honor y el dinero, sujeto compuesto y gramatical; son, verbo sustantivo; apetecibles, atributo simple y gramatical.

P. ¿Qué razón hay para llamar compuesto al sujeto?

R. ¿No da idea de dos sujetos distintos?

P. Es verdad. Haced de suerte que no parezca compuesto ese sujeto.

R. Tengo que sacar dos proposiciones, sirviéndome para cada una de ellas del mismo atributo y poniendo el verbo en singular.

P. Mostrad cómo.

R. El honor es apetecible.- El dinero es apetecible.

P. ¿Por qué ponéis el verbo en singular?

R. Porque en singular está el sujeto honor (120).

Cierra la exposición con un "suplemento a la sintaxis", en el cual bajo la forma dialógica aborda algunos aspectos que pueden plantear dificultades, por ejemplo, en relación con el género de los sustantivos: 
R. Adoptar semejante doctrina fuera reconocer variación en el género mismo; es decir, en el sexo, y ya se ve el error, pues que ni el masculino puede ser femenino, ni este masculino. Cuando se dice que hombre es un sustantivo, si varía haciéndose plural en la voz hombres, no puede llamarse variación suya la voz mujer, sustantivo de distinto nombre y de distinto género, aunque a la propia especie pertenece (124).

Finalmente, expone su objetivo didáctico:

Bastan los precedentes ejemplos para que el maestro ordene un sistema de análisis razonada, escogiendo aquellas sentencias que más a propósito le parecieren. Es nuestro objeto indicar un método de enseñanza útil y sencillo (129).

Reyes escapa al esquematismo de los ejemplos armados por el gramático y en la parte destinada a mostrar el análisis propio del ámbito escolar recurre a un fragmento de Iriarte, autor de fábulas que tuvieron amplia difusión, reconociendo la importancia del desarrollo del gusto literario en la escuela secundaria y su propia filiación ilustrada. Propone el "ejemplo de un período en verso analizado lógicamente":
Allá en tiempo de entonces,
Y en tierras muy remotas,
Cuando hablaban los brutos
Su cierta jerigonza,
Notó el sabio Elefante
Que entre ellos era moda
Incurrir en abusos
Dignos de gran reforma.
(Iriarte)

Como "la construcción de este período es artificial: por consiguiente se ha cometido la figura llamada hipérbaton" se hace la transformación a la "construcción natural" (pensada como necesaria para "poner en orden las ideas", que constituye también un objetivo de la enseñanza media): "El sabio Elefante notó que, incurrir en abusos dignos de gran reforma era moda entre ellos, allá en tierras muy remotas, y en tiempo de entonces, cuando los brutos hablaban su cierta jerigonza". El texto poético permite en su transformación destacar los dos tipos de construcción y hacer posible un análisis que atienda a la jerarquía y dependencia de los constituyentes. El primer paso es el reconocimiento de las proposiciones: "El sabio Elefante nota que, 'proposición principal'; incurrir en abusos dignos de gran reforma era moda entre ellos, allá en tierras muy remotas y en tiempos de entonces, 
'proposición incidente principal', y cuando los brutos hablaban su cierta jerigonza, 'proposición incidente secundaria"' (80). Pero esto es insuficiente ya que el autor señala que la unión de la oración (periodo) es superior a aquella primera división, de allí que haya que partir del recorte entre sujeto (El sabio Elefante) y predicado (el resto) que es en el marco de la oración el primer nivel de análisis, cuyo alcance supera el de cada proposición ya delimitada. La designación del todo es vacilante ya que se usa periodo, al inicio, o proposición: "Como las tres proposiciones que hemos enumerado tienen una conexión tan íntima, que no podríamos separarlas sin dejar incompleto el sentido, es de necesidad analizarlas como si formasen una sola proposición". Todo el detenido desarrollo que sigue consiste en la división, que va a ser habitual en el estructuralismo, en constituyentes inmediatos jerarquizados aunque esté ausente el dispositivo gráfico de "cajones" y en la utilización de un criterio funcional. Ejemplificamos con un fragmento:

La primera palabra del atributo es notó, que concierta con el sujeto en número y persona, y que, como verbo activo, está modificado por el complemento directo que incurrir en abusos, \&a: este complemento consta de término solo y su palabra principal es que, sustantivo neutro y anunciativo de la proposición incidente incurrir en abusos, \&a. El sujeto de esta proposición es incurrir en abusos dignos de gran reforma; y el atributo lo que queda del período. El elemento principal de sujeto es incurrir, el cual viene modificado por el complemento ordinario en abusos dignos de gran reforma; este complemento consta de preposición y término, preposición en y término abusos dignos de gran reforma; palabra principal de este término abusos, modificado por la frase adjetiva dignos de gran reforma, palabra principal de esta frase dignos modificado por el complemento ordinario de gran reforma, que consta de preposición y término, preposición de y término gran reforma; palabra principal del término reforma, modificada por el adjetivo gran apocopado.

Son evidentes la ausencia de rasgos latinizantes, la importancia asignada al armado gramatical y no lógico del "período" y la proximidad con el análisis sintáctico por constituyentes inmediatos, tal como va a implementarse en la escuela secundaria varias décadas después, en el cual se va de las unidades sintáctico funcionales mayores a las más pequeñas.

De Fossey propone un "análisis de lexigrafía" antes de tratar la sintaxis. Elige también una fábula de Iriarte y va caracterizando cada palabra: $a$, preposición; la, artículo determinado, femenino singular; Pulga, nombre común, femenino singular, usado con el sentido de nombre propio; ... En la sintaxis, después del desarrollo de las funciones, cuya larga enumeración muestra que considera más las relaciones de proximidad de los segmentos 
que las jerárquicas (sujeto, verbo determinante, régimen directo, calificativo, atributo, complemento indirecto, complemento posesivo, complemento común, determinado común, determinado posesivo, determinado supino y palabras intercalares o incidentes), propone el cuadro de un "modelo de análisis de sintaxis" que divide una oración en proposiciones en la primera columna; en la segunda, separa los sintagmas de cada una sin un criterio jerárquico pero transformando la construcción en directa; $y$, en la tercera, le asigna las funciones. El ejemplo es: Vino cierto día un padre de familia a ver a Aristipo (principal absoluta), que era uno de los mayores filósofos de la Grecia (incidente explicativa), le suplicó (principal relativa) que admitiese a un hijo suyo en el número de sus discípulos (incidente determinativa).

Ejemplificamos con el primer tramo (75):

Un padre sujeto

de familia complemento posesivo

vino verbo determinante

a ver determinado supino

a Aristipo régimen directo

cierto día (es decir en cierto día) complemento común

Luego presenta una "tabla sinóptica de los seis casos en que puede hallarse el nombre en la proposición" (76), poniendo primero el equivalente en castellano y separando en singular y en plural utilizando un sustantivo animado y otro inanimado para mostrar la diferencia en el acusativo:

Sujeto o nominativo El padre El libro

Complemento posesivo o genitivo Del padre Del libro

Complemento indirecto o dativo Al padre o para el padre Al libro o para el...

Régimen directo o acusativo Al padre El libro

Vocativo Padre, ó padre Libro, ó libro

Complemento común o ablativo Con, sin, de, por, \&c.el p. Con .....el libro.

En el Compendio, el modelo de análisis está inserto en el tramo correspondiente a la sintaxis figurada. Se parte de un ejemplo de construcción regular: Don Alonso, Rey de Aragón, decía que ganaba el afecto de los vasallos buenos con la justicia, y que ganaba el afecto de los vasallos malos con la clemencia.

El análisis, predominantemente lineal, combina categorías de distinta procedencia: la tradición latinizante de los casos, las clasificaciones de oraciones suministradas por la misma gramática (primeras y segundas) y las categorías asociadas con los aspectos tradicionales de construcción, 
concordancia y régimen. Cito el comienzo del análisis en el que revisa las categorías consideradas en los apartados anteriores:

En este ejemplo, que consta de tres oraciones, ligadas una a otra, se observan con toda exactitud las reglas del régimen y construcción regular. El nombre propio D. Alonso, nominativo de todas, está colocado en primer lugar, y con las palabras Rey de Aragón, que le particularizan, precede al verbo decía, al cual sigue la conjunción que, formando ella y el resto de la cláusula otras dos oraciones que sirven de acusativo a la primera y en las cuales se observa el mismo orden. Los sustantivos afectos, vasallos, justicia y clemencia, llevan antepuestos sus artículos correspondientes, unos masculinos y otros femeninos, unos en número singular, en plural otros. El verbo determinante decía, regido por el nominativo Alonso, se halla en tercera persona del pretérito imperfecto del indicativo, concertado con él en número y persona, y lo mismo el verbo determinado ganaba que, con el auxilio de la conjunción que, se une dos veces al verbo decía, del cual es regido (114).

Invirtiendo la operación de Reyes, al análisis sucede el fragmento de autor (Saavedra, Empr. 22), que ejemplifica la construcción figurada:

Pues este mismo ejemplo pasa a ser de construcción figurada en uno de los autores clásicos de nuestra lengua, que escribe: Decía el Rey D. Alonso de Aragón que con la justicia ganaba el afecto de los buenos, y con la clemencia el de los malos. Es de construcción figurada esta cláusula, porque se altera el orden natural, anteponiendo el verbo decía al nominativo Alonso; la preposición con ... (114).

El ejemplo, propio de la literatura política, remite a la historia nacional y a la concepción de gobierno, tendiendo a formar desde ese lugar las subjetividades estatales.

\section{CONCLUSIÓN}

La década del cincuenta del siglo XIX es un tramo interesante para indagar en la enseñanza de la gramática en la escuela secundaria, ya que preludia la expansión de este nivel, para la cual son necesarios textos destinados a los jóvenes que se desprendan de los que apuntan globalmente a las primeras letras. Partir de un corte sincrónico para estudiar algunos de sus exponentes 
permite identificar en ellos perspectivas compartidas así como tendencias que se van definiendo, aspectos que todavía no se reconocen, desplazamientos en el tratamiento de viejos temas que esbozan las nuevas preocupaciones, vacilaciones y búsquedas. Consideramos con Delesalle y Chevalier (1986: 15) que toda obra gramatical escolar es un espacio no clausurado que tiende a resolver en conjunto postulaciones difícilmente sistematizables, de allí que relacionemos varias de aquellas producidas en la misma década para vislumbrar el interdiscurso de época. Si bien nos hemos detenido en cada uno de los textos en relación con los ejes de contraste elegidos, los abordaremos, entonces, conjuntamente para señalar las orientaciones que nos parecen más significativas y respecto de las cuales se irán definiendo los textos posteriores. Así como podemos reconocer distintas temporalidades en las que se inscriben los saberes gramaticales, también podemos pensar en los aspectos que serán retomados en diferentes momentos y lugares a lo largo de más de un siglo y por obra de diferentes factores. Por ejemplo, el criterio sintáctico dominante en la gramática de Bello se impondrá, aunque no en forma homogénea ni continua, en Argentina gracias a las reformulaciones pedagógicas (de las cuales hemos atendido a la de Reyes), pero también al recurso al texto fuente (que circulará por algunos establecimientos secundarios), al retome operado por la Gramática Castellana (1938-1939) de Amado Alonso y Pedro Henríquez Ureña (Arnoux 2001) y a su recuperación por parte del estructuralismo. Esta perspectiva convivirá con otras, académicas o que se combinan con postulados de las gramáticas generales, según las relaciones de fuerza del campo educativo y gramatical.

En la etapa considerada, la oración va conceptualizándose como unidad gramatical reconocible en la escritura con sus rasgos de sentido completo y autonomía sintáctica marcada por el punto. Se pasa así de una gramática de la proposición a una de la oración. El período es la categoría que sirve para el paso de la proposición lógica, expresión de un juicio, a la oración ligada en términos generales a la actitud del hablante, de lo cual una primera aproximación es reconocer tipos como oración interrogativa, expositiva, imperativa, a lo que marginalmente los textos se refieren. La necesidad de la enseñanza en este nivel de la lectura y la escritura de textos complejos hace ingresar otros tipos de subordinación además de las proposiciones de relativo modificadoras de un núcleo sustantivo (como en D. V. la "proposición referencial"). La noción de complemento permite esta ampliación y anuncia a su vez lo que será el complemento circunstancial, introducido en algunos casos como "complemento ordinario", restringido a modificador del verbo construido con preposición.

El tema de las figuras si bien es una herencia de la reflexión gramatical desencadenada por el problema del orden en las lenguas vernáculas europeas 
deviene, gracias a la presencia de figuras diferentes del hipérbaton, el lugar para pensar los efectos de sentido ligados a la colocación de los términos (particularmente del adjetivo), la variación en el juego de los clíticos, las modalidades de enunciación determinadas por factores pragmáticos, la modulación estilística o la diferencia entre perfilamiento del evento y concordancia gramatical. La enálage, por su parte, permite insistir en la relación función / clases de palabras, que las gramáticas generales habían planteado y que se va a imponer cuando lo hagan los criterios sintácticos en la definición de las clases.

Las zonas destinadas al análisis muestran las vacilaciones respecto de las operaciones intelectuales requeridas por este nivel educativo. Encontramos, por un lado, el análisis gramatical (centrado en las palabras) y el lógico (que atiende a las proposiciones), ya transitados, que se amplían con la determinación de las funciones, aunque de segmentos aislados linealmente. También reaparecen, por el otro, las operaciones de ordenamiento sintáctico requeridas para el análisis de textos particularmente complejos como son los poéticos (Arnoux 2012a). Pero lo importante es la aceptación gradual de los espacios mayores, sujeto y atributo / predicado (no aplicados solo a la proposición sino a la oración / período) como marco del análisis. A esto sigue la delimitación de núcleos y modificadores y, en relación con estos, el establecimiento de diferentes clases y la utilización de sustituciones y transformaciones para el reconocimiento de los regidos por el verbo. Así como el análisis tripartito (sujeto / verbo / atributo) ya es dejado de lado, la coordinación entre proposiciones del nivel primero del análisis no ha hecho todavía su entrada. La ejercitación es vista, por algunos, como la posibilidad de ir de las estructuras mayores a las unidades menores recorriendo jerárquicamente la superficie discursiva sin dejar huecos ni apelar a la elipsis. Otros privilegian una determinación lineal de las unidades y la consideración de cada proposición por separado, desdeñando la concepción global de la oración. Los textos destinados a este nivel deberán optar, lo que implica también optar por un modo de pensar que se podrá aplicar a otros objetos.

Habíamos señalado, desde una perspectiva glotopolítica, que las gramáticas participan en la construcción del imaginario nacional naturalizando la representación de una lengua común, que disciplinan las prácticas gracias a la norma que exponen y que intervienen en la estructura de clases formando diferencialmente a la población. En relación con el sector que asiste, en la primera etapa, a los establecimientos de enseñanza secundaria se tenderá, asimismo, a desarrollar la capacidad de abstracción, la aplicación de criterios "racionales" (regulares y económicos), el reconocimiento y apropiación de las formas prestigiadas por los buenos escritores y la habilidad de leer y escribir textos complejos. A alcanzar esos objetivos en la formación de 
la élite se orientan, aunque por trayectos diferentes y con mayor o menor énfasis, los textos gramaticales que estudiamos.

\section{FUENTES}

Bello, Andrés. 1928 [1847]. Gramática castellana, destinada al uso de los americanos, París: Andrés Blot, editor.

D. V. 1851. Principios elementales de gramática castellana recopilados de los mejores autores. Dispuestos para el uso de la juventud. Buenos Aires: Imprenta Republicana.

De Fossey, Mathieu. 1855. Compendio de la gramática castellana, con anotaciones para la ilustración de los profesores de primeras letras. Guanajuato: Tipografía de Juan Evaristo Oñate.

Real Academia Española. 1857. Compendio de la gramática de la lengua castellana, dispuesto por la Real Academia Española para la segunda enseñanza. Madrid: Imprenta Nacional.

Reyes, José Olegario. 1854. Compendio de gramática castellana, compuesto y arreglado a las doctrinas de la gramática del Sr. D. Andrés Bello. La edición consultada es la de Pablo Coni, Buenos Aires, 1868.

\section{REFERENCIAS BIBLIOGRÁFICAS}

Arnoux, Elvira Narvaja de. 2001. Disciplinar desde la lengua. La Gramática Castellana de Amado Alonso y Pedro Henríquez Ureña. En Elvira Narvaja de Arnoux y Angela di Tullio (comp.). Homenaje a Ofelia Kovacci, pp. 53-76. Buenos Aires: Eudeba.

2008. Los discursos sobre la nación y el lenguaje en la formación del Estado chileno (1842-1862). Estudio glotopolítico. Buenos Aires: Santiago Arcos.

2012a. La primera gramática escolar 'general' publicada en Buenos Aires en los años de la Independencia: la Gramática Española o Principios de la Gramática General aplicados a la Lengua Castellana de Felipe Senillosa. Histoire, Epistémologie, Langage 34 (2): 43-62.

2012b. La reformulación interdiscursiva en los textos gramaticales: en torno a la gramática académica de 1854. Conferencia leída en las I Jornadas de Historia de la Lingüística, Universidad de Buenos Aires, 1-3 de agosto de 2012 (entregado al Instituto de Lingüística para su publicación).

2013. Grammar and the state in the Southern Cone in the nineteenth century. En José Del Valle (ed.). A Political History of Spanish. The Making of a Language, pp. 152166. Cambridge: Cambridge University Press.

Blanco, María Imelda. 1997. Reformulaciones de la Gramática castellana de Andrés Bello destinadas a la escuela media. Letterature d'America 59: 87-126.

2005. La enseñanza de la lengua nacional en los colegios secundarios argentinos. Tesis de Maestría en Ciencias del Lenguaje, Instituto Superior del Profesorado "Joaquín V: González".

Calero Vaquera, María Luisa. 1986. Historia de la gramática española (1847-1920. De Bello a Lenz). Madrid: Gredos. 
2007. Desarrollo de la sintaxis en la tradición gramatical hispánica. En Josefa Dorta, Cristóbal Corrales y Dolores Corbella (eds.). Historiografía de la lingüistica en el ámbito hispánico. Fundamentos epistemológicos y metodológicos, pp. 89-118. Madrid: Arco/Libros.

2008. Análisis lógico y análisis gramatical en la tradición española: hacia una (r)evolución de la sintaxis. Gramma-temas 3 ["España y Portugal en la tradición gramatical'"]: 11-42.

ChÁvez, Fermín. 1973. La cultura en la época de Rosas. Buenos Aires: Theoría.

Chevalier, Jean-Claude. 1968. Histoire de la Syntaxe. Naissance de la notion de complément dans la grammaire française (1530-1750). Ginebra: Droz.

1979. Analyse grammaticale et analyse logique: esquisse de la naissance d'un dispositif scolaire. Langue Française 41: 20-34.

Delesalle, Simone y Jean-Claude Chevalier. 1986. La linguistique, la grammaire et l'école, 1750-1914. Paris: Armand Colin.

Foucault, Michel. 2006. Seguridad, territorio, población. Buenos Aires: Fondo de Cultura Económica.

García Folgado, María José. 2006. La gramática general y la institución escolar en España: inicios. En Antonio Roldán Pérez (coord.). Caminos actuales de la historiografía lingüistica: actas del V Congreso Internacional de la Sociedad Española de Historiografía Lingüística, pp. 651-662. Murcia: Universidad de Murcia.

Gómez Asencio, José J. 1987. Naissance et développement de la notion de phrase composée dans les grammaires espagnoles (1771-1851). Histoire, Epistémologie, Langage 9 (2): $117-132$

2014. Tratamiento de la sintaxis en gramáticas españolas del último tercio del siglo XVIII. En Sylvie Archaimbault, Jean-Marie Fournier y Valérie Raby (eds.). Penser l'histoire des savoirs linguistiques. Hommage à Sylvain Auroux, vol. 2. Lyon: ENS Éditions.

GutiéRrez, JuAn María. 1915. Origen y desarrollo de la enseñanza pública superior en Buenos Aires. Buenos Aires: "La cultura argentina".

HaßLER, GERDA. 2012. Los conceptos de ‘análisis lógico'y 'análisis gramatical' en gramáticas de la primera mitad del siglo XIX. Revista Argentina de Historiografia Lingüistica IV (1): 23-37.

LÉPINETTE, BRIGITTE. 2008. La penetración del modelo gramatical 'general' de tipo escolar en España. Historiographia Linguistica XXXV (3): 305-341.

Luis, CARLos. 1997. La sección "Sintaxis" en la gramática hispánica del siglo XIX. Letterature d'America 59: 9-36.

Moreno de Alba, José G. 2006. Apuntes sobre algunas gramáticas del siglo XIX. En La Biblioteca Nacional. Triunfo de la República. México, D. F.: UNAM.

Mourelle-Lema, Manuel. 1968. La teoría lingüística en la España del siglo XIX. Madrid: Editorial Prensa española.

Munguía Escamilla, Estela. 2010. Fossey: francés transmisor de ideas y saberes en el México decimonónico. En Eduardo Rey Tristán y Patricia Calvo González (eds.). XIV Encuentro de Latinoamericanistas Españoles: congreso internacional, pp. 1298-1315. Santiago de Compostela: Universidad de Santiago de Compostela.

Puiggrós, Adriana. 2013. Qué pasó en la educación argentina. Buenos Aires: Galerna.

Seguin, JeAn-Pierre. 1993. L'invention de la phrase au XVIIIe siècle. Lovaina-Paris: Éditions Peeters.

Solari, Manuel H. 2006. Historia de la educación argentina. Buenos Aires: Paidós.

Stefanini, Jean. 1994. Sur la notion de phrase et son histoire. En Histoire de la grammaire, pp. 177-185. Paris: CNRS Editions. 